\title{
ORIGINAL ARTICLE Plant-derived flavanol (- )epicatechin mitigates anxiety in association with elevated hippocampal monoamine and BDNF levels, but does not influence pattern separation in mice
}

\author{
TP Stringer, D Guerrieri, C Vivar and H van Praag
}

Flavanols found in natural products such as cocoa and green tea elicit structural and biochemical changes in the hippocampus, a brain area important for mood and cognition. Here, we evaluated the outcome of daily consumption of the flavanol ( - )epicatechin ( $4 \mathrm{mg}$ per day in water) by adult male C57BL/6 mice on measures of anxiety in the elevated plus maze (EPM) and open field (OF). Furthermore, pattern separation, the ability to distinguish between closely spaced identical stimuli, considered to be mediated by the hippocampal dentate gyrus (DG), was tested using the touchscreen. To investigate mechanisms through which ( - )epicatechin may exert its effects, mice were injected with bromodeoxyuridine $\left(50 \mathrm{mg} \mathrm{kg}^{-1}\right)$ to evaluate adult hippocampal neurogenesis. In addition, monoaminergic and neurotrophin signaling pathway proteins were measured in tissue derived from subject cortices and hippocampi. Flavanol consumption reduced anxiety in the OF and EPM. Elevated hippocampal and cortical tyrosine hydroxylase, downregulated cortical monoamine oxidase-A levels, as well as increased hippocampal brain-derived neurotrophic factor (BDNF) and pro-BDNF support the flavanol's anxiolytic effects. In addition, elevated pAkt in hippocampus and cortex was observed. (-) Epicatechin ingestion did not facilitate touchscreen performance or DG neurogenesis, suggesting a non-neurogenic mechanism. The concurrent modulation of complementary neurotrophic and monoaminergic signaling pathways may contribute to beneficial mood-modulating effects of this flavanol.

Translational Psychiatry (2015) 5, e493; doi:10.1038/tp.2014.135; published online 6 January 2015

\section{INTRODUCTION}

Studies in humans and animal models have shown that dietary interventions rich in plant polyphenols may alleviate stress or anxiety and mitigate cognitive decline..$^{1-3}$ Cocoa, green tea, blueberries and grapes contain flavanols, a subclass of plant polyphenols with pleiotropic roles in neuroprotection, ${ }^{4-7}$ cognition $^{2,8}$ and mood. ${ }^{9,10}$ The active ingredient that confers these benefits often remains unclear, as most investigations examine whole foods or multiple flavanols ${ }^{11-14}$ in animal models of aging, ${ }^{15,16}$ cerebrovascular stress $^{17}$ or Alzheimer's disease. ${ }^{18-22}$ As such, a pure flavanol of particular interest is (-)epicatechin (EC), which traverses the blood-brain barrier and may directly affect brain function. ${ }^{22-24}$ EC consumption improves memory in mice ${ }^{24}$ and snails. ${ }^{25}$ Its metabolites enhance long-term potentiation in hippocampal slices derived from Alzheimer's diseasemodeling mice. ${ }^{22}$

It is unknown whether this flavanol may also affect mood regulation. Indeed, both green tea and grape seed flavanols act as antidepressants in mice, enhancing performance in the forcedswim and tail suspension tests. ${ }^{26-28}$ Similar observations were made in rats consuming a cocoa polyphenol (88.5\% tannins, $11.5 \%$ flavanols) mixture. ${ }^{29}$ Studies of individual flavanols corroborate these findings; the green tea catechin (-)epigallocatechin gallate improved mouse performance in multiple assays of anxiety, ${ }^{9,10}$ whereas the flavanol luteolin decreased immobility time in the forced-swim test in mice. ${ }^{30}$ In humans, consumption of a flavanol-rich cocoa drink attenuated anxiety precipitated by a demanding cognitive task. ${ }^{31}$ These polyphenols may influence mood by modulating the monoaminergic systems, increasing neurotransmitter synthesis ${ }^{32}$ and decreasing enzymatic breakdown/removal. ${ }^{17,33}$ Furthermore, as decreased brain-derived neurotrophic factor (BDNF) levels are associated with adult depression, ${ }^{34,35}$ neurotrophin expression may also undergird flavanol-driven mood improvements.

Dietary polyphenols, such as the Chinese herb Xiaobuxin-Tang (XBXT-2) and curcumin, increased adult dentate gyrus (DG) neurogenesis in models of chronic stress, ${ }^{32,36-39}$ suggesting another mechanism of action by which flavanols may exert mood-modulating effects. Although in female mice ingestion of EC did not influence new DG cell survival, ${ }^{24}$ effects on differentiation of adult-born neurons in male mice have not been evaluated. The DG, and in particular adult neurogenesis, is considered important for pattern separation. ${ }^{40,41}$ Indeed, in aging humans flavanol consumption improved DG function and performance on a task requiring discrimination between highly similar visual stimuli. ${ }^{42}$ This ability to make fine distinctions may also be relevant to mood regulation, by preventing overgeneralization and thereby reducing anxiety. ${ }^{43}$ However, whether EC consumption provokes anxiolytic effects remains to be determined. Altogether, the aim of the present study is to evaluate effects of EC on pattern separation and anxiety, and to determine the underlying cellular mechanisms.

Neuroplasticity and Behavior Unit, Laboratory of Neurosciences, Intramural Research Program, National Institute on Aging, National Institutes of Health, Biomedical Research Center, Baltimore, MD, USA. Correspondence: Dr H van Praag, Neuroplasticity and Behavior Unit, Laboratory of Neurosciences, Intramural Research Program, National Institute on Aging, National Institutes of Health, Biomedical Research Center, Suite 100, 251 Bayview Boulevard, Baltimore, MD 21224, USA.

E-mail: vanpraagh@mail.nih.gov

Received 7 September 2014; revised 19 October 2014; accepted 17 November 2014 


\section{MATERIALS AND METHODS}

Subjects and compound administration

Subjects. Male C57BL/6J mice (The Jackson Laboratory, Bar Harbor, ME, USA) were housed individually in standard cages at 6 weeks of age with a standard day/night cycle: lights were switched on at 0600 hours and off at 1800 hours. Animals were constrained to $90 \%$ of their free-feeding weight throughout the study. At 18 weeks of age, mice received for 5 days a daily intraperitoneal injection of bromodeoxyuridine (BrdU; dissolved in $0.9 \%$ saline, filtered sterile at $0.2 \mu \mathrm{m}, 50 \mathrm{mg} \mathrm{kg}^{-1}$ body weight at $10 \mu \mathrm{g} \mathrm{ml}^{-1}$. Sigma Aldrich, St Louis, MO, USA) to label dividing cells. Following completion of behavioral testing, animals were deeply anesthetized at 28 weeks of age via inhalation of isoflurane and perfused transcardially with $0.9 \%$ saline (room temperature). The hippocampi and overlying cortices were dissected out of the left hemispheres and stored at $-80^{\circ} \mathrm{C}$ for use in immunoblotting. The right hemispheres were stored in $4 \%$ paraformaldehyde at $4{ }^{\circ} \mathrm{C}$ for subsequent immunohistochemical experiments. After $96 \mathrm{~h}$ in paraformaldehyde, tissue to be used for immunohistochemistry was equilibrated in $30 \%$ sucrose. Sequential coronal sections $(40 \mu \mathrm{m})$ were taken through the hippocampus and stored in phosphatebuffered glycerol at $-20^{\circ} \mathrm{C}$. Animals were maintained in accordance with the National Institutes of Health guidelines. All protocols for procedures were approved by the NIA's Institutional Animal Care and Use Committee.

$(-) E C$ administration. At 10 weeks of age, mice underwent shaping and conditioning to the touchscreen system for 4 weeks. At 14 weeks, mice were assigned to control (CON) or EC-treatment groups ( $n=15$ per group) that had been counterbalanced based on performance during touchscreen shaping. Animals were administered either standard water or a treatment liquid comprised of EC (Sigma, St Louis, MO, USA) dissolved in water at a concentration of $0.667 \mathrm{mg} \mathrm{ml}^{-1}$. Fresh solution was made every other day. Using Nanodrop 2000 (Thermo Scientific, Waltham, MA, USA), absorbance of EC solution at $276 \mathrm{~nm}$ was measured after 24 and $48 \mathrm{~h}$ to confirm negligible variations $(0.2 \% \pm 0.3$ and $1.4 \% \pm 0.3$ absorbance of fresh solution, respectively) due to EC oxidation. Treatment was available ad libitum and based on an average water consumption of $6 \mathrm{ml}$ per day (that is, $\sim 4 \mathrm{mg}$ EC daily). Total duration of EC consumption was 14 weeks.

\section{Spatial pattern separation in the touchscreen}

Animals were shaped to the touchscreen chamber, which housed a sixwindow grid and a reward trough (Lafayette Instruments, Lafayette, IN, USA), at 10 weeks of age for 4 weeks. Shaping began by habituating the mice to the chamber for 2 days. Pavlovian training, a 1-h session, taught the animals to associate stimulus interaction (that is, nose poking an illuminated grid square) with the sounding of a tone and the dispensation of a liquid reward (strawberry milk, Nesquik, Vevey, Switzerland). The subsequent 3-day 'must touch' phase required stimulus interaction to trigger reward presentation. 'Must initiate' training taught the mice to initiate the next trial via a nose poke to the reward trough. During 'punish incorrect,' the final stage of shaping, an aversion toward interacting with non-stimulus grid squares was instilled through inversion of the house light and imposition of a short time-out period prior to trial resumption.

Shaping was followed by EC administration beginning at 14 weeks of age. The mice then participated in 5 days of task training. To reach criterion in this phase, the subjects were required to select the correct (that is, programmed to trigger liquid reward) choice from two identical but spatially discrete stimuli in seven out of eight consecutive trials. To progress to the next stage, subjects had to attain criterion at least once during three out of four consecutive days of training. During the sequent 16-day interval of probe trials, animals attempted to reach the prenominate criterion when presented with stimuli separated by larger and smaller distances than in task training. All touchscreen protocols were performed as described previously. ${ }^{44}$

\section{Anxiety tests}

Open field. Mice were placed individually in an open-field (OF) arena $(27.3 \times 27.3 \mathrm{~cm}$, height $20.3 \mathrm{~cm})$ housed within a sound-attenuating cubicle (Med Associates, St Albans, VT, USA) and permitted to move freely. Trials lasted for $30 \mathrm{~min}$. Animal motion and cumulative path length were automatically tracked via three 16 -beam infrared array and recorded by Activity Monitor software (Version 4.0, Med Associates).

Elevated plus maze. Animals were individually placed in the center of an elevated plus maze (EPM) (constructed on-site, made of white Plexiglas,
Total Plastics, Baltimore, MD, USA) on a $60-\mathrm{cm}$ high stand, each arm $30 \mathrm{~cm} \times 5 \mathrm{~cm}$, closed arms wall $16 \mathrm{~cm}$ high, $5 \mathrm{~cm} \times 5 \mathrm{~cm}$ center platform) and allowed to explore freely for $5 \mathrm{~min}$. Time spent in the open and closed arms were recorded in semiautomatic fashion by video tracking software (ANY-maze, Stoelting, Wood Dale, IL, USA).

\section{Adult neurogenesis histology}

BrdU immunohistochemistry and cell counts. A one-in-six series of freefloating sections $(40 \mu \mathrm{m})$ was washed in tris-buffered saline (TBS) and preincubated with $0.6 \% \mathrm{H}_{2} \mathrm{O}_{2}$ for $30 \mathrm{~min}$ to quench endogenous peroxidases. After rinsing, the sections were incubated in $2 \mathrm{~N} \mathrm{HCl}$ at $37^{\circ} \mathrm{C}$ for $30 \mathrm{~min}$ to denature DNA and then neutralized in $0.1 \mathrm{M}$ borate buffer at room temperature. After thorough washing, the sections were blocked with TBS ++ (3\% donkey serum, $0.05 \mathrm{M}$ tris-buffered saline, $0.5 \%$ Triton- $\mathrm{X} 100)$ for $30 \mathrm{~min}$ at room temperature and incubated with rat anti-BrdU (1:200, Accurate Chemical, Westbury, NY, USA) overnight at $4{ }^{\circ} \mathrm{C}$. Thereafter, the sections were washed and immersed in biotin-SP-conjugated donkey antirat IgG (1:250, Jackson ImmunoResearch, West Grove, PA, USA) followed by $2 \mathrm{~h}$ in $\mathrm{ABC}$ reagent (Vectastain Elite; Vector Laboratories, Burlingame, $\mathrm{CA}$, USA). The sections were then incubated with the substrate 3,3diaminobenzidine (Sigma) for $5 \mathrm{~min}$ to visualize the cells that had incorporated BrdU. BrdU-positive cells were counted in a one-in-six series of sections ( $240 \mu \mathrm{m}$ apart) through a $\times 20$ objective (Olympus, BX51, Center Valley, PA, USA) throughout six sections per animal starting at the rostrocaudal granule cell layer as described previously. ${ }^{44}$

Double-immunofluorescence staining and new cell phenotype analysis. After denaturation, neutralization, washing and blocking steps described above, free-floating sections (1:12 series, $480 \mu \mathrm{m}$ apart) were co-incubated with primary antibodies, anti-rat $\mathrm{BrdU}(1: 100$, Accurate Chemical) and the neuronal marker anti-mouse NeuN (1:100, Millipore, Billerica, MA, USA) for $72 \mathrm{~h}$ at $4^{\circ} \mathrm{C}$. Therafter, sections were co-incubated with donkey anti-rat Alexa Fluor 488 (1:250, Thermo Fisher, Waltham, MA, USA) and donkey anti-mouse Cy3 (1:250, Jackson ImmunoResearch) for $2 \mathrm{~h}$ at room temperature. Thirty $\mathrm{BrdU}^{+}$cells in the DG per animal were randomly selected and imaged for phenotype analysis (Olympus FV1000). The percentage of $\mathrm{BrdU}^{+} / \mathrm{NeuN}^{+}$cells was calculated.

\section{Western blotting}

Immunoblotting was employed in samples derived from in vivo administration of the compound to determine its effects on relative expression of neurotrophins, their receptors, kinases, transcription factors and neurotransmitters. Cortices and hippocampi derived from the left hemispheres of mice that had ingested the compound for 14 weeks were homogenized and quantified via the Bradford assay (lysis buffer: RIPA lysis buffer (Millipore) with Complete ULTRA tablets (Roche, Basel, Switzerland)). Thirty micrograms of protein from homogenized tissue were denatured via boiling and separated on a polyacrylamide gel. Proteins were then transferred to Immobilon-FL membranes (Millipore), which were treated with rabbit anti- $\beta$-tubulin (1:2500, Li-Cor Biosciences, Lincoln, NE, USA), rabbit anti-Akt, rabbit anti-phospho-Akt (1:1000, Cell Signaling Technologies, Danvers, MA, USA), rabbit anti-phospho-ERK 1/2, mouse anti-ERK 1/2, mouse anti-CREB, rabbit anti-phospho-CREB (1:1000, Santa Cruz Biotechnologies, Santa Cruz, CA, USA), rabbit anti-MAO-B (1:3000, Sigma Aldrich), goat anti-MAO-A (1:1000, Santa Cruz Biotechnologies), mouse anti-pro-BDNF (1:7500, GeneCopoeia, Rockville, MD, USA), rabbit anti-BDNF (1:500, Santa Cruz Biotechnologies), rabbit anti-tyrosine hydroxylase (1:200, Abcam, Cambridge, MA, USA), and rabbit anti-glyceraldehyde-3-phosphate dehydrogenase (GADPH, 1:1000, Sigma Aldrich). Membranes were then tagged with $800 \mathrm{CW}$ fluorescent goat anti-mouse or anti-rabbit IRDye (1:15 000), read in an OdysseyR infrared imager (Li-Cor Biosciences, Lincoln, $\mathrm{NE}$, USA), and evaluated using Odyssey 2.0 software (Li-Cor Biosciences), Precision Plus Protein Ladder (Bio-Rad, Hercules, CA, USA) was used as a marker.

\section{Statistical analysis}

Student's $t$-test was used for behavioral, immunohistological and immunoblotting experiments with a $P$-value cutoff of 0.05 . All statistical analyses were carried out using Statview (Abacus Corporation, Baltimore, $M D, U S A)$. 


\section{RESULTS}

$(-)$ EC has no effect on spatial pattern separation

Mice were trained in a pattern-separation task in the touchscreen. ${ }^{44}$ After 1 month of shaping protocols in the touchscreen, mice ( $n=15$ per group) were given standard drinking water or water supplemented with EC for the duration of the experiments (Figure 1a). Animal weights were taken at monthly intervals and did not differ between cohorts at the onset of flavanol treatment (CON: $19.66 \pm 0.29 \mathrm{~g}$; EC: $19.43 \pm 0.26 \mathrm{~g}$ ) or end (CON: $27.0 \pm 0.36 \mathrm{~g}$; EC: $26.71 \pm 0.39 \mathrm{~g})$ of the study $(P>0.34)$.

Following the shaping period, subjects underwent 6 days of task training in which they discriminated between visually identical, spatially discrete stimuli with an intermediate separation to gain a liquid reward. No difference was found in the average number of days each group required to complete task training
(CON, $3.6 \pm 0.16$ days; EC, $3.6 \pm 0.19$ days; $P=1.00$ ). During probe trials, which alternated between testing big and small separations, the EC and CON cohorts evinced no difference in performance [small separation: CON, 49.04 \pm 3.72 ; EC, $51.29 \pm 4.02$ trials to criterion $\left(t_{(28)}=1.17, P>0.70\right)$; big separation: CON, $29.92 \pm 2.30$; $E C, 26.11 \pm 1.73$ trials to criterion $\left(t_{(28)}=0.38, P>0.25\right)$ ], (Figure $\left.1 \mathrm{~b}\right)$. Overall, these data suggest that there is not a selective effect of EC on the DG-related pattern-separation function.

\section{$(-)$ EC does not affect adult neurogenesis}

To determine whether $(-) E C$ administration has a role in hippocampal newborn cell survival, mice were injected with BrdU daily for 5 days at 18 weeks of age. Post mortem, immunohistochemical staining and quantification of BrdU-labeled cells in the
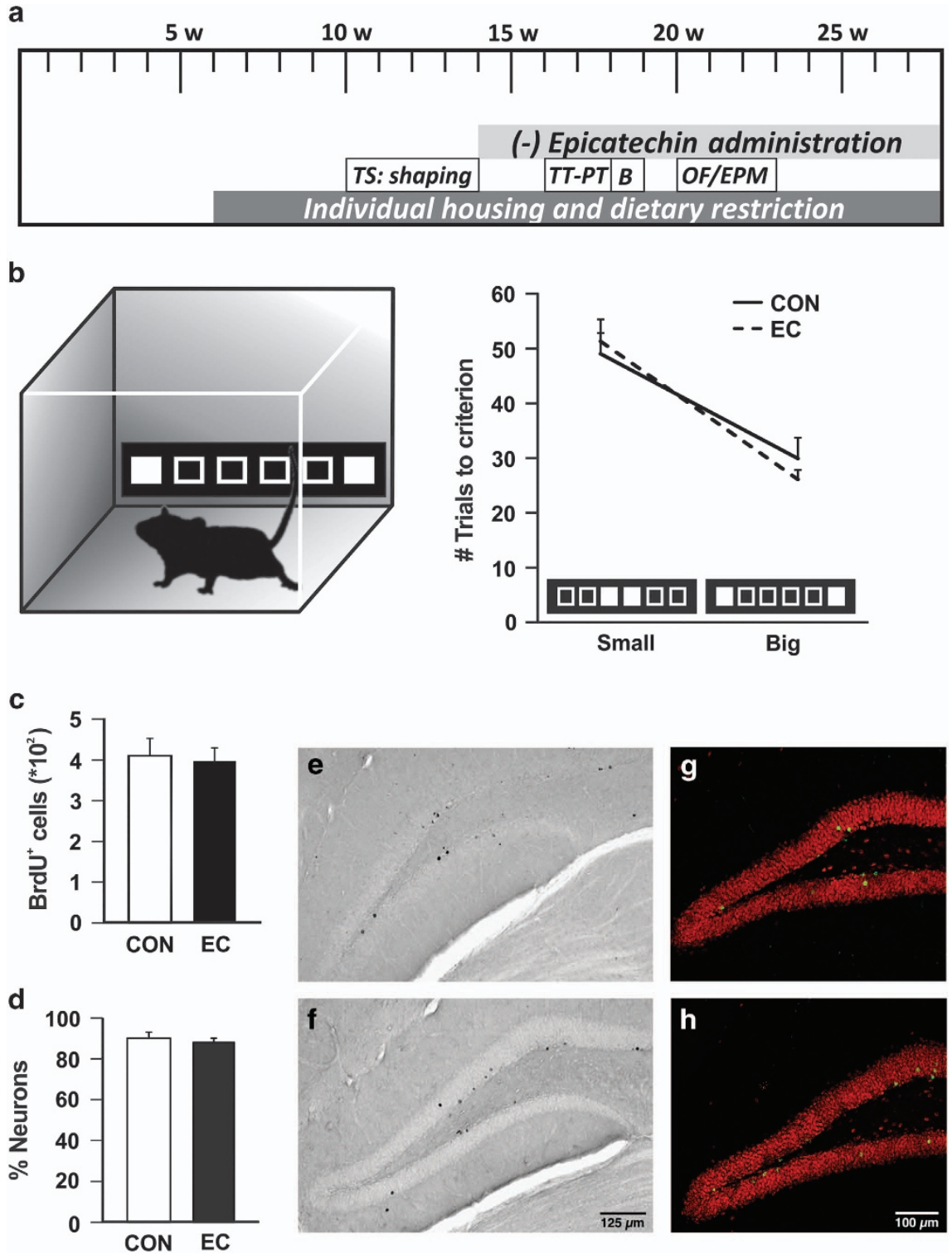

Figure 1. Pattern separation and adult hippocampal neurogenesis. (a) Timeline of the experiments (TS, touchscreen; TT, task training; PT, probe trials; B, BrdU injections; OF, open field; EPM, elevated plus maze; w, weeks of age). (b) The touchscreen paradigm acquisition of big and small separation between two identical stimuli was tested in control (CON) and (-)epicatechin (EC)-treated mice, which were trained to reach a criterion where seven of eight trials were performed correctly. Pattern separation did not differ between the CON and EC groups when the separation between the stimuli was either large or small. (c) Bromodeoxyuridine (BrdU)-positive cell number did not differ between the groups. (d) The percentage of new DG neurons showed no differences between CON and EC-treated mice. Photomicrographs of new cells surviving 9 weeks after the last BrdU injection, in tissue derived from (e) CON and (f) EC-treated subjects. Neuronal phenotype was determined by double-labeling for BrdU (green) and NeuN (red) in (g) CON and (h) EC-treated mice. Error bars denote s.e.m. 
right DG was undertaken (CON, $409 \pm 42$ cells, $n=9$; EC, $397 \pm 32$ cells, $n=10$; Figures $1 c$, e and f). No difference in the number of surviving newborn DG cells was observed $\left(t_{(17)}=0.23, P>0.82\right)$. In addition, co-expression analysis of BrdU and NeuN (CON, $n=6$; EC, $n=6$ ) for neuronal phenotype was performed. There was no difference between the groups in percentage of BrdU/NeuNpositive cells $\left(t_{(10)}=0.65, P>0.53\right.$; Figures $1 \mathrm{~d}, \mathrm{~g}$ and $\left.\mathrm{h}\right)$. The absence of a neurogenic effect is consistent with the observed lack of change by $(-)$ EC consumption in spatial pattern separation.

\section{Effects of (-)EC administration on OF and EPM behavior}

To determine whether EC exerts anxiolytic effects similar to those reported for green-tea flavanols ${ }^{9}$ and cocoa flavonoids, ${ }^{29}$ mice were tested in the OF paradigm for $30 \mathrm{~min}$. No significant difference was found between the total distance travelled by each cohort [CON, $102.8 \mathrm{~m} \pm 5.1 \mathrm{~m}$; EC, $100.4 \mathrm{~m} \pm 5.5 \mathrm{~m} ; t_{(28)}=0.29$, $P>0.77)]$. However, the ratio of time spent in the central region of the field compared with time in the periphery was significantly higher in the EC-treatment animals compared with the CON group [CON, $\left.0.203 \pm 0.009 ; \mathrm{EC}, 0.249 \pm 0.01\left(t_{(28)}=3.59, P<0.002\right)\right]$, as well as the ratio of the distance travelled in the central region compared with the distance in the periphery [CON, $0.097 \pm 0.006$; EC, $\left.0.119 \pm 0.008\left(t_{(28)}=2.31, P<0.03\right)\right]$, (Figures $2 a$ and $\left.b\right)$. The OF data suggest that EC consumption mitigates anxiety.

These results were supported by the outcome of subject evaluation in the EPM trials, an assay to evaluate anxiety-like behavior. ${ }^{45}$ The mice were monitored in the EPM over a 5 -min period. The CON animals spent a significantly higher amount of time in the closed arms of the maze than in the open arms [open arms, $\quad 90.2 \pm 6.1 \mathrm{~s} ; \quad$ closed arms, $126.8 \pm 6.5 \mathrm{~s} \quad\left(t_{(28)}=4.11\right.$, $P<0.0003)]$. The EC-treatment mice, on the other hand, spent equal amounts of time in the open and closed arms [open arms, $103.2 \pm 6.8 \mathrm{~s}$; closed arms, $\left.112.3 \pm 6.1 \mathrm{~s} ;\left(t_{(28)}=1.005, P>0.32\right)\right]$, (Figure 2c). Altogether, ( - EC appears to function as an anxiolytic that promotes exploratory behavior.

EC consumption modulates expression of mood-related proteins Treatments of mood disorders generally aim to increase the availability of monoamines (norepinephrine, serotonin and dopamine) in the brain. To determine whether the effects of EC are mediated through monoaminergic mechanisms, we performed immunoblotting experiments with homogenized hippocampal and cortical tissue (CON, $n=5-7 ; \mathrm{EC}, n=5-7)$. EC consumption increased tyrosine hydroxylase $(\mathrm{TH})$ levels in both hippocampus $\left(1.51\right.$-fold $\left.\mathrm{EC} / \mathrm{CON} ; t_{(12)}=2.63, P<0.03\right)$ and cortex (1.79-fold EC/CON; $\left.t_{(12)}=3.22, P<0.01\right)$, (Figures $2 \mathrm{~d}$ and e). A decrease in expression of monoamine oxidase-A (MAO-A), which metabolizes serotonin, norepinephrine and dopamine, was observed in cortex (0.69-fold, $\left.t_{(11)}=2.22, P<0.05\right)$ of $E C$ consuming animals compared with the CON groups, but not in hippocampi $\left(0.92\right.$-fold EC/CON; $\left.t_{(12)}=1.08, P>0.30\right)$, whereas MAO-B, which metabolizes dopamine, remained unchanged in both hippocampus $\left(t_{(11)}=1.31, P>0.21\right)$ and cortex $\left(t_{(11)}=0.48\right.$, $P>0.64$ ), (Figures $2 d$ and e). Together these data suggest that EC ingestion modulates mood by increasing monoaminergic neurotransmitter synthesis and by concurrently inhibiting their enzymatic degradation.

\section{EC elevates hippocampal pro-BDNF and mature BDNF protein levels}

To determine whether the precursor of BDNF (pro-BDNF) and mature BDNF may instantiate the observed anxiolytic effects, we performed immunoblotting experiments with homogenized hippocampal and cortical tissue (CON, $n=5-7 ; \mathrm{EC}, n=5-7)$. Hippocampal tissue from animals treated with EC was found to contain significantly higher levels of pro-BDNF (1.74-fold; $\left.t_{(11)}=2.58, P<0.03\right)$ and mature BDNF (1.34-fold; $t_{(12)}=2.19$, $P<0.05)$ compared with the CON group (Figure 3a). However, neurotrophin proteins were not changed in cortex (Figure $3 b$ ), suggesting that the modulation of BDNF is specific to the hippocampus. To further investigate the effects of EC upon the BDNF signaling pathway, we evaluated the levels of protein kinase $B$ (Akt), extracellular-signal-regulated kinase 2 (ERK2) and CAMP response element-binding protein (CREB) phosphorylation. EC intake induced significant increase of the levels of pAkt in the hippocampus (1.47-fold; $t_{(12)}=2.20, P<0.05$; Figure $3 c$ ) and in the cortex (2.33 fold; $t_{(11)}=2.79, P<0.02$; Figure $3 d$ ). Neither pERK2 [hippocampus $\left(t_{(12)}=0.58, P>0.57\right)$; cortex $\left(t_{(11)}=0.14, P>0.89\right)$ ] nor pCREB [hippocampus $\left(t_{(12)}=0.37, P>0.72\right)$; cortex $\left(t_{(12)}=1.32\right.$, $P>0.21$ )] were modified by the intake of EC (Figures $3 e$ and $f$ ).

\section{DISCUSSION}

In this study, we show that EC consumption alleviated anxiety in the OF and EPM. These behavioral changes may be attributed to alterations in relevant signaling pathways. Specifically, EC intake concurrently increased hippocampal and cortical $\mathrm{TH}$ levels and diminished production of cortical MAO-A, but not MAO-B. Increased monoamine levels may lead to the observed elevation in pro-BDNF and BDNF protein levels in the hippocampi of ECsupplemented animals. In addition, increased levels of pAKT, but not $\mathrm{pCREB}$ or $\mathrm{pERK}$, were found in both hippocampus and cortex. Adult hippocampal neurogenesis and spatial pattern separation remained unchanged, suggesting a non-neurogenic mechanism of action of this flavanol. Altogether, our data provide support for EC as an anxiolytic compound that concurrently affects multiple complementary cell signaling pathways.

Pattern separation, which is the distinct encoding of very similar events or stimuli, ${ }^{46}$ is deemed closely linked to adult neurogenesis ${ }^{44}$ and BDNF protein levels, ${ }^{47}$ and considered relevant to both memory and mood regulation. ${ }^{43}$ Our results indicate that EC had no effect on adult neurogenesis, consistent with an absence of improvement in the touchscreen patternseparation tasks. The lack of a neurogenic effect is consistent with our previous study ${ }^{24}$ and recent research by others. ${ }^{48}$ Other dietary polyphenols, such as the Chinese herb Xiaobuxin-Tang (XBXT-2) and curcumin, have been demonstrated to boost cell proliferation. ${ }^{32,36-39}$ However, these studies used rodent models of chronic stress ${ }^{32,36,38}$ with likely a lower baseline rate of neurogenesis. It may be that flavonoids enhance neurogenesis in models of stress and pathology via their antioxidant and antiinflammatory properties, mitigating oxidative damage to promote cell survival and differentiation. ${ }^{49}$ However, in young healthy animals no change in neurogenesis was evident after 3 months of compound consumption, suggesting that other components of polyphenol-enriched diets may mediate potential neurogenic effects.

The anxiolytic and antidepressant effects of dietary polyphenols have been reported in a growing number of studies, both in humans ${ }^{50}$ and in animal models. ${ }^{29,36,51}$ The EPM has been used to show a decrease in anxiety-induced behavior in polyphenol-fed animals; for instance, OF1 mice supplemented with green tea leaves improved their performance in the EPM test. ${ }^{9}$ Our results from the OF and EPM led us to posit that EC affected dopaminergic or serotonergic systems, common targets of anxiolytic drugs. ${ }^{52}$ Immunoblotting data showed that $\mathrm{TH}$, an enzyme critical to monoamine synthesis, was produced in far greater amounts in the cortices and hippocampi of ECsupplemented mice than in CON. This finding is consistent with previous studies, showing polyphenol-induced $\mathrm{TH}$ overexpression both in vitro, for instance by rosmarinic acid of Rosmarinus officinalis, ${ }^{53}$ and in vivo in $\mathrm{C} 57$ mice by teaflavin of black tea. ${ }^{54}$ Further, MAO-A, an enzyme that deaminates and catalyzes 
a

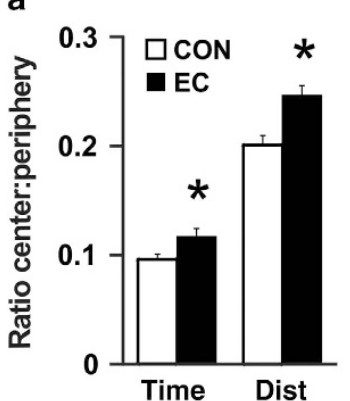

b

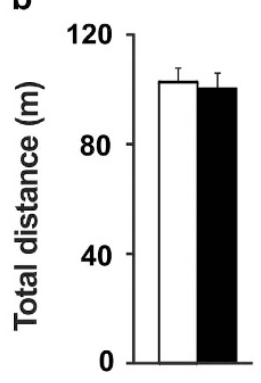

C

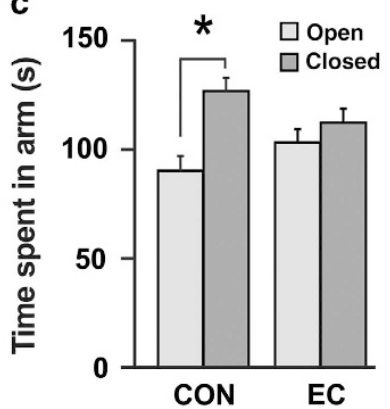

d
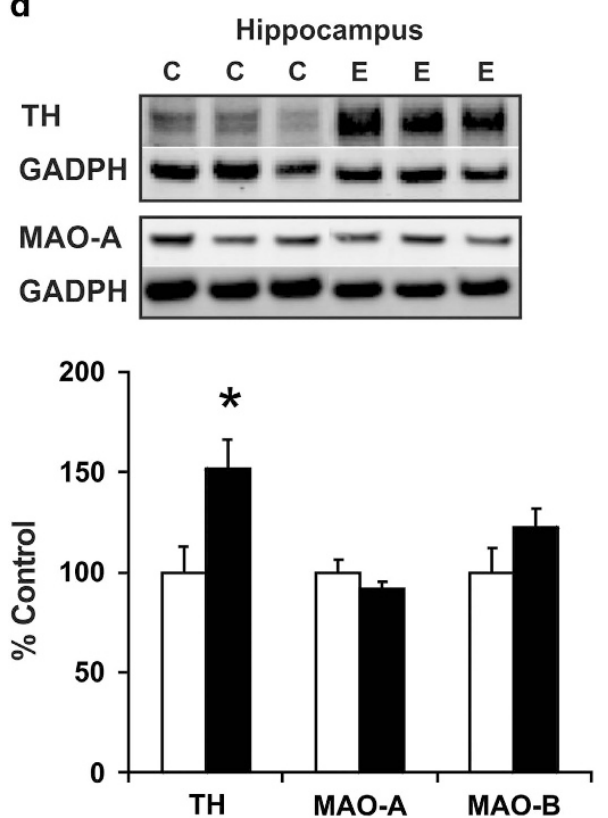

e

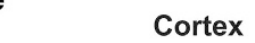

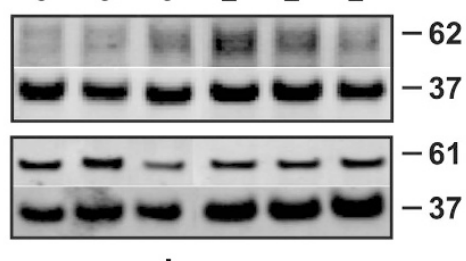

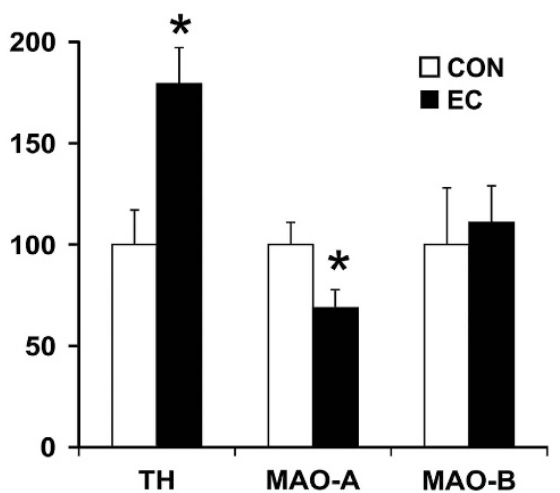

Figure 2. Behavioral and cellular assays relevant to mood. (a-c) Anxiety was assayed in the open field (OF) and the elevated plus maze (EPM). (a) Animals were placed inside the OF chamber for 30 min following 7 weeks of ( - )epicatechin (EC) consumption. The ratio of time spent and of distance (DIST) travelled by EC subjects in the center of the chamber, relative to the periphery, was significantly higher than that of controls (CON). (b) Total distance travelled in the OF did not differ between the groups. (c) In the EPM, subjects consuming EC displayed no preference between the open or closed arms, whereas CON animals spent a significantly greater amount of time in the closed arms than in the open arms. (d and e) Hippocampi and cortices were assayed for tyrosine hydroxylase (TH), monoamine oxidase (MAO)-A and MAO-B. (d) EC-consuming animals evinced significantly greater hippocampal expression of TH. (e) Increased expression of TH and a reduction in MAO-A was observed in the cortices of EC-supplemented animals $\left({ }^{*} P<0.05\right)$. GADPH, glyceraldehyde-3-phosphate dehydrogenase. Error bars denote s.e.m.

synaptic serotonin and dopamine, ${ }^{55}$ was found to be expressed in significantly lower levels in the cortices of EC-treated mice. Indeed, berry anthocyanins ${ }^{56}$ and Uncaria rhynchophylla, ${ }^{57}$ extracts rich in flavanols, inhibit MAOs in vitro. These results suggest that EC consumption leads to increased production of dopamine coupled with greater availability of synaptic dopamine and serotonin and so may help alleviate anxiety. Our data are consistent with in vitro assays, demonstrating that flavanols can enhance serotonergic function. ${ }^{27,33}(-)$ Epigallocatechin gallate, curcumin and transresveratrol have been found to inhibit the activity of MAOs, thereby boosting performance in assays of rat depression. ${ }^{26,50,58}$ It should be noted that (-)EC increases hippocampal angiogenesis, ${ }^{24}$ possibly by regulation of nitric oxide synthase. ${ }^{59,60}$ Interestingly, nitric oxide has been linked to anxiety and serotonin receptor signaling ${ }^{61}$ and may be another mechanism, in addition to the concurrent MAO-A inhibition and TH upregulation observed in this study, which mediates anxiolytic effects of $(-)$ EC in vivo.

Elevated monoamine levels may result in increased neurotrophin levels. ${ }^{62}$ The neurotrophin hypothesis of depression postulates that antidepressant and anxiolytic therapeutic drugs might exert their effects through BDNF upregulation in the hippocampus (for a review, see Martinovich et al. ${ }^{53}$ ). Hippocampal BDNF messenger RNA levels increase by administration of chemical antidepressants, ${ }^{64}$ and BDNF administration in rodents reverses depression-related behaviors in rodents. ${ }^{65,66}$ The reason for EC's enhancement of hippocampal rather than cortical neurotrophin levels remains unclear at present. In aged rats, administration of a diet containing a mixture of EC and (+)catechin similarly provoked a predominant increase in BDNF messenger RNA levels the hippocampus. ${ }^{13}$ In addition, a flavanol-containing diet elevated hippocampal BDNF levels in rats that were not behaviorally tested. ${ }^{67}$ Interestingly, our data show that levels of pro-BDNF also increased notably in mouse hippocampus after EC administration. The role of pro-BDNF overall, ${ }^{68}$ and in depression in particular, has not been well understood, ${ }^{69}$ however, our data suggest that EC may result in processing of the precursor to increase mature BDNF levels by an as yet undefined mechanism.

The combined increment in pro-BDNF and BDNF by EC in the hippocampus may reduce anxiety. It would be of interest to test 
a

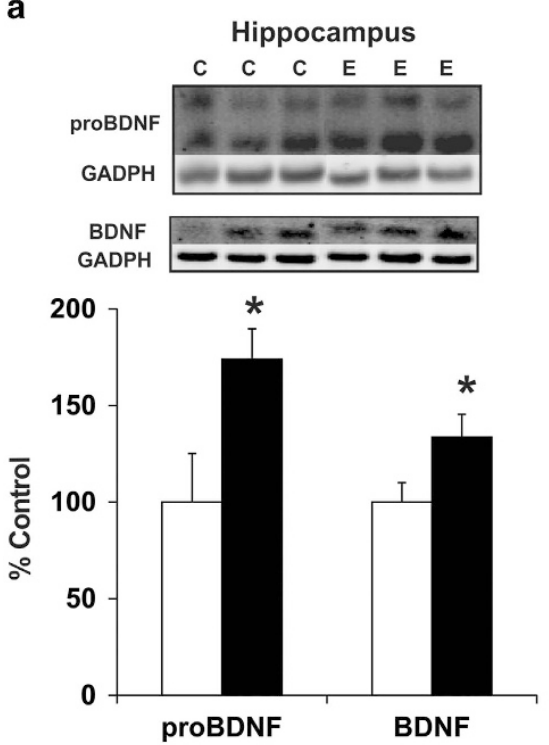

C
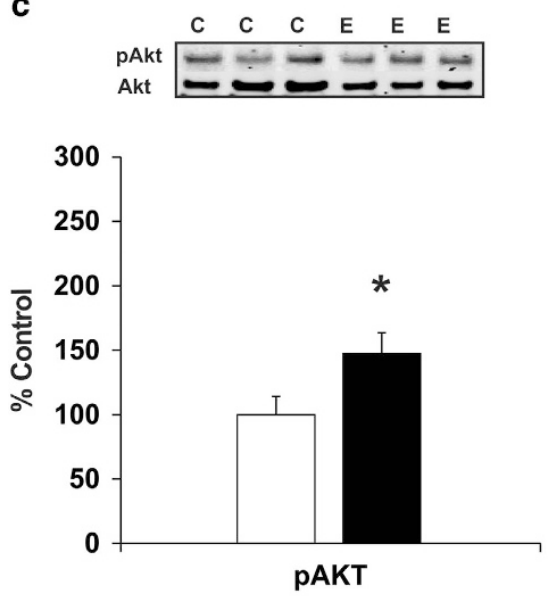

e
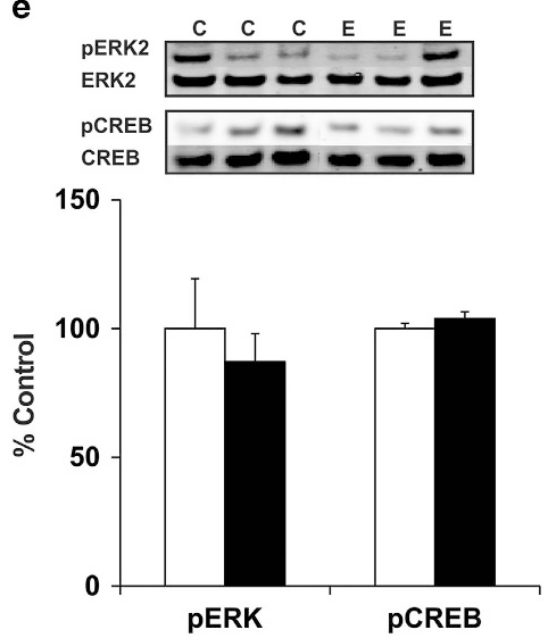

b
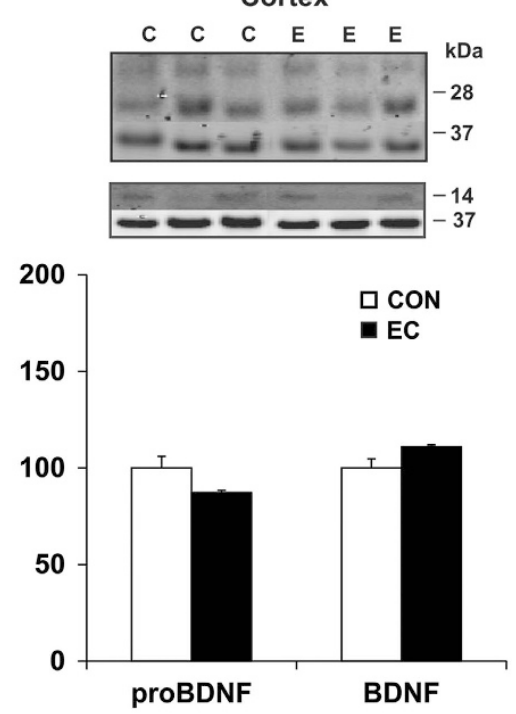

d
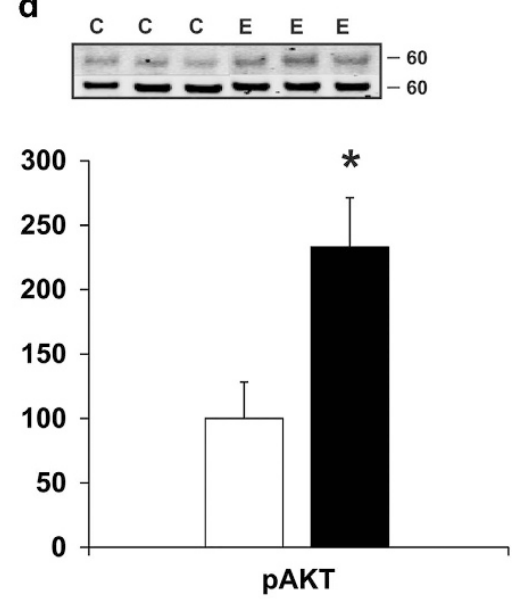

f

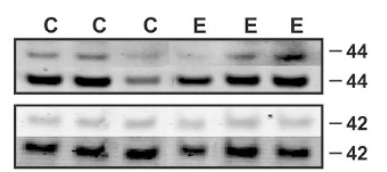

150

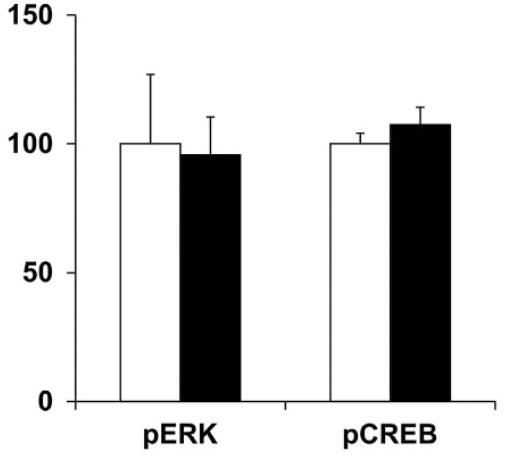

Figure 3. Neurotrophin brain-derived neurotrophic factor (BDNF) and related signaling pathway proteins. (a and b) Immunoblotting of hippocampal and cortical tissue derived from the behaviorally tested animals. (a) (-)Epicatechin (EC)-consuming animals evinced significantly greater expression of pro-BDNF and BDNF proteins in the hippocampus. (b) Growth factor levels did not change in the cortex. (c and d) EC increased the expression of pAkt in the hippocampus and cortex with respect to the control group. (e and f) Neither pERK2 nor pCREB levels were modified by the intake of EC in the hippocampus and cortex. ( $\left.{ }^{*} P<0.05\right)$. Error bars denote s.e.m. 
EC in the context of the Val66Met polymorphism, a singlenucleotide mutation that hampers the secretion and trafficking of BDNF. ${ }^{70}$ Men homozygous for the met allele are more susceptible to adult depression and suffer from more acute symptoms than non-carriers; the mutation is associated with a higher risk of childhood and geriatric depression generally. ${ }^{35,71-73}$ In both mice and humans, this polymorphism causes decrements in episodic memory $^{70}$ and extinction learning, ${ }^{74}$ whereas mouse models prove refractory to rescue of plasticity by antidepressants. ${ }^{75}$ The effects wrought by the Val66Met mutation seem to lie at antipodes to those of chronic EC administration. Although these studies do not necessarily suggest that increased expression of BDNF would obtund anxiety or improve memory, it is not unreasonable to hypothesize that hippocampal BDNF may be the point of articulation that links EC consumption to cognition and mood. Indeed, improvement of memory function associated with phytochemical consumption ${ }^{13,24,76}$ may be mediated in part by reduced anxiety resulting from BDNF modulation.

BDNF can trigger phosphatidylinositide-3 kinase-dependent signaling, ${ }^{77}$ relevant to antidepressant effects. ${ }^{78} \mathrm{~A}$ major component of this signaling pathway is protein kinase $B$ (also known as Akt, a factor considered important for synaptic plasticity ${ }^{68}$ ), which targets and inhibits glycogen synthase kinase 3 (GSK3). In mouse models, Akt-induced inhibition of GSK3 decreased anxiety and reduced tendency to develop depression. ${ }^{79}$ Our immunoblotting results showed increased activated Akt in both hippocampi and cortices in EC-supplemented mice. These data, together with an increase of BDNF and pro-BDNF and the lack of change in other BDNF-dependent pathways components such as ERK and CREB, support the hypothesis that EC exerts anxiolytic effects via BDNF activation of the Akt pathway in the hippocampus. Indeed, a closer study of the components and the targets of the PIK3-Akt signaling pathway would be of interest to determine whether different isoforms ${ }^{80}$ may be upregulated in hippocampus and cortex. For example, Akt1 is involved in bipolar disorder ${ }^{81}$ and growth. ${ }^{82}$ Akt3 is crucial for brain development, ${ }^{83}$ whereas Akt2 has been identified as the main isoform for anxiety and depression behavior in mice. ${ }^{84}$ It would be interesting to study whether there is divergent regulation of Akt isoforms by EC consumption in different brain areas. Indeed, the mechanism underlying Akt induction in cortex is unclear. It is possible that a specific flavanol receptor, such as has been described in arterial endothelial cells ${ }^{85}$ might be expressed in the brain ${ }^{8}$ and activate the Akt signaling pathway, having a role in anxiety regulation.

Overall, our findings indicate that chronic (-)EC administration evokes mood-related benefits through the modulation of monoaminergic and neurotrophic systems. It is our hope that this work will serve as a rachis for future attempts to uncover the workings of this flavanol, as well as open options for a more natural way to improve human mood disorders.

\section{CONFLICT OF INTEREST}

The authors declare no conflict of interest.

\section{ACKNOWLEDGMENTS}

This work was supported by the Intramural Research Program of the National Institute on Aging. We thank Sarah Collica for technical assistance and Linda Kitabayashi for preparation of the photomicrograph.

\section{REFERENCES}

1 Joseph JA, Shukitt-Hale B, Willis LM. Grape juice, berries, and walnuts affect brain aging and behavior. J Nutr 2009; 139: 1813S-1817S.

2 Spencer JP. The impact of fruit flavonoids on memory and cognition. Brit J Nutr 2010; 104: S40-S47.

3 Andújar I, Recio MC, Giner RM, Ríos JL. Cocoa polyphenols and their potential benefits for human health. Oxid Med Cell Longev 2012; 2012: 906252.
4 Reznichenko L, Amit T, Youdim MB, Mandel S. Green tea polyphenol (-) epigallocatechin-3-gallate induces neurorescue of long-term serum deprived serum deprived PC12 cells and promotes neurite outgrowth. J Neurochem 2005; 93: 1157-1167.

5 Davinelli S, Sapere N, Zella D, Bracale R, Intrieri M, Scapagnini G. Pleiotropic protective effects of phytochemicals in Alzheimer's disease. Oxid Med Cell Longev 2012; 2012: 386527.

6 Sokolov AN, Pavlova MA, Klosterhalfen S, Enck P. Chocolate and the brain: neurobiological impact of cocoa flavanols on cognition and behavior. Neurosci Biobehav Rev 2013; 37: 2445-2453.

7 Schimidt HL, Vieira A, Altermann C, Martins A, Sosa P, Santos FW et al. Memory deficits and oxidative stress in cerebral ischemia-reperfusion: Neuroprotective role of physical exercise and green tea supplementation. Neurobiol Learn Mem 2014; 114C: 242-250.

8 van Praag H. Exercise and the brain: something to chew on. Trends Neurosci 2009; 32: $283-290$.

9 Vignes M, Maurice T, Lanté F, Nedjar M, Thethi K, Guiramand J et al. Anxiolytic properties of green tea polyphenol (-)epigallocatechin gallate (EGCG). Brain Res 2006; 1110: 102-115.

10 Chen W, Zhao X, Wang D, Li S, Hou Y, Hong Y et al. Effects of epigallocatechin-3gallate on behavioral impairments induced by psychological stress in rats. Exp Biol Med 2010; 235: 577-583.

11 Ramirez MR, Izquierdo I, Raseria MCB, Zuanazzi JA, Barros D. Effect of lyophilized vaccinium berries on memory, anxiety, and locomotion in adult rats. Pharmacol Res 2005; 52: 457-462.

12 Assunção M, Santos-Marques MJ, Carvalho F, Lukoyanov NV, Andrade JP. Chronic green tea consumption prevents age-related changes in rat hippocampal formation. Neurobiol Aging 2011; 32: 707-717.

13 Rendeiro C, Vauzour D, Rattray M, Waffo-Teguo P, Merillon JM, Butler LT et al. Dietary levels of pure flavonoids improve spatial memory performance and increase hippocampal Brain-derived neurotrophic factor. PLOS One 2013; 8: e63535.

14 Allam F, Dao AT, Chugh G, Bohat R, Jafri F, Patki G et al. Grape powder supplementation prevents oxidative stress-induced anxiety-like behavior, memory impairment, and high blood pressure in rats. J Nutr 2013; 143: 835-842.

15 Joseph JA, Shukitt-Hale B, Denisova NA, Bielinski D, Martin A, McEwen JJ et al. Reversals of age-related declines in neuronal signal transduction, cognitive, and motor behavioral deficits with blueberry, spinach, or strawberry dietary supplementation. J Neurosci 1999; 19: 8114-8121.

16 Rodrigues J, Assuncao M, Lukoyanov N, Cardoso A, Carvalho F, Andrade JP. Protective effects of a catechin-rich extract on the hippocampal formation and spatial memory in aging rats. Behav Brain Res 2013; 246: 94-102.

17 Xu Y, Zhang J, Xiong L, Zhang L, Sun D, Liu H. Green tea polyphenols inhibit cognitive impairment induced by chronic cerebral hypoperfusion via modulating oxidative stress. J Nutr Biochem 2010a; 21: 741-748.

$18 \mathrm{Li} \mathrm{Q}$, Zhao HF, Zhang ZF, Liu ZG, Pei XR, Wang JB et al. Long-term green tea catechin administration prevents spatial learning and memory impairment in senescence-accelerated mouse prone- 8 mice by decreasing A $\beta$ 1-42 oligomers and upregulating synaptic plasticity-related proteins in the hippocampus. Neuroscience 2009; 163: 741-749.

19 Zeng YQ, Wang YJ, Zhou XF. Effects of (-)epicatechin on the pathology of APP/PS1 transgenic mice. Front Neurol 2014; 5: 69.

20 Cuevas E, Limon D, Pérez-Severiano F, Díaz A, Ortega L, Zenteno E et al. Antioxidant effects of Epicatechin on the hippocampal toxicity caused by Amyloidbeta 25-35 in rats. Eur J Pharm 2009; 616: 122-127.

21 Hou Y, Aboukhatwa MA, Lei DL, Manaye K, Khan I, Luo Y. Anti-depressant natural flavonols modulate BDNF and beta amyloid in neurons and hippocampus of double TgAD mice. Neuropharmacology 2010; 58: 911-920.

22 Wang J, Ferruzzi MG, Ho L, Blount J, Janle EM, Gong B et al. Brain-targeted proanthocyanidin metabolites for Alzheimer's disease treatment. J Neurosci 2012; 32: $5144-5150$.

23 Abd el Mohsen MM, Kuhnle G, Rechner AR, Schroeter H, Rose S, Jenner P et al. Uptake and metabolism of epicatechin and its access to the brain after oral ingestion. Free Radical Biol Med 2002; 33: 1693-1702.

24 van Praag $\mathrm{H}$, Lucero MJ, Yeo GW, Stecker K, Helvand K, Heivand N et al. Plantderived flavanol (-) Epicatechin enhances angiogenesis and retention of spatial memory in mice. J Neurosci 2007; 27: 5869-5878.

25 Fruson L, Dalesman S, Lukowiak K. A flavonol present in cocoa [(-)epicatechin] enhances snail memory. J Exp Biol 2012; 215: 3566-3576.

26 Xu Y, Li S, Chen R, Li G, Barish PA, You W et al. Antidepressant-like effect of low molecular proanthocyanidin in mice: Involvement of monoaminergic system. Pharmacol, Biochem Behav 2010b; 94: 447-453.

27 Xu Y, Wang Z, You W, Zhang X, Li S, Barish PA et al. Antidepressant-like effect of trans-resveratrol: Involvement of serotonin and noradrenaline system. Eur Neuropsychopharmacol 2010c; 20: 405-413. 
28 Zhu WL, Shi HS, Wei YM, Wang SJ, Sun CY, Ding ZB et al. Green tea polyphenols produce antidepressant-like effects. Pharm Res 2012; 65: 74-80.

29 Messaoudi M, Bisson JF, Nejdi A, Rozan P, Javelot H. Antidepressant-like effects of a cocoa polyphenolic extract in Wistar-Unilever rats. Nutr Neurosci 2008; 6: 269-276.

30 Ishisaka M, Kakefuda K, Yamauchi M, Tsuruma K, Shimazawa M, Tsuruta A et al. Luteolin shows an antidepressant-like effect via suppressing endoplasmic reticulum stress. Biol Pharm Bull 2011; 34: 1481-1486.

31 Scholey AB, French SJ, Morris PJ, Kennedy DO, Milne AL, Haskell CF. Consumption of cocoa flavanols results in acute improvements in mood and cognitive performance during sustained mental effort. J Psychopharm 2009; 24: 1505-1514.

32 Valente T, Hidalgo J, Bolea I, Ramirez B, Angles N, Reguant J et al. A Diet enriched in polyphenols and polyunsaturated fatty acids, LMN diet, induces neurogenesis in the subventricular zone and hippocampus of adult mouse brain. Jour Alz Dis 2009; 18: 849-865.

33 Rocha FF, Lima-Landman MTR, Souccar C, Tanae MM, De Lima TCM, Lapa AJ. Antidepressant-like effect of Cecropia glazioui Sneth and its constituents in vivo and in vitro characterization of the underlying mechanism. Phytomed 2007; 14: 396-402.

34 Nibuya M, Morinobu S, Duman RS. Regulation of BDNF and trkB mRNA in rat brain by chronic electroconvulsive seizure and antidepressant drug treatments. Neurosci 1995; 15: 7539-7547

35 Erickson Kl, Miller DL, Roecklein KA. The aging hippocampus: interactions between exercise, depression, and BDNF. Neuroscientist 2012; 18: 82-97.

36 An L, Zhang YZ, Yu NJ. The total flavonoids extracted from Xiaobuxin-Tang upregulate the decreased hippocampal neurogenesis and neurotrophic molecules expression in chronically stressed rats. Prog Neuropsychopharmocol Biol Psych 2008; 32: 1484-1490.

37 Kim SJ, Son TG, Park HR, Park M, Kim MS, Kim HS et al. Curcumin stimulates proliferation of embryonic neural progenitor cells and neurogenesis in the adult hippocampus. J Biol Chem 2008; 283: 14497-14505.

38 Tiwari SK, Agarwal S, Seth B, Yadav A, Nair S, Bhatnagar P et al. Curcumin-loaded nanoparticles potently induce adult neurogenesis and reverse cognitive deficits in Alzheimer's disease model via canonical Wnt/ $\beta$-catenin pathway. ACS Nano 2014 8: 76-103.

39 Stangl D, Thuret S. Impact of diet on adult hippocampal neurogenesis. Genes Nutr 2009; 4: 271-282.

40 Marr D. Simple memory: a theory for archicortex.Trans $R$ Soc Lond B Biol Sci 1971 262: 23-81.

41 Sahay A, Scobie KN, Hill AS, O'Carroll CM, Kheirbek MA, Burghardt NS et al. Increasing adult hippocampal neurogenesis is sufficient to improve pattern separation. Nature 2011; 472: 466-470.

42 Brickman AM, Khan UA, Provenzano FA, Yeung LK, Suzuki W, Schroeter $\mathrm{H}$ et al. Enhancing dentate gyrus function with dietary flavanols improves cognition in older adults. Nat Neurosci 2014; 17: 1798-1803.

43 Castrén E, Hen R. Neuronal plasticity and antidepressant actions. Trends Neurosci 2013; 36: 259-267.

44 Creer DJ, Romberg C, Saksida LM, van Praag H, Bussey TJ. Running enhances spatial pattern separation. Proc Natl Acad Sci USA 2010; 107: 2367-2372.

45 Belzung C, Griebel G. Measuring normal and pathological anxiety-like behavior in mice: a review. Behav Brain Res 2001; 125: 141-149.

46 Gilbert PE, Kesner RP, Lee I. Dissociating hippocampal subregions: A double dissociation between dentate gyrus and CA1. Hippocampus 2001; 11: 632-636.

47 Bekinschtein P, Kent BA, Oomen CA, Clemenson GD, Gage FH, Saksida LM et al. BDNF in the dentate gyrus is required for consolidation of 'pattern-separated' memories. Cell Rep 2013; 5: 759-768.

48 Gibbons TE, Pence BD, Petr G, Ossyra JM, Mach HC, Bhattacharya TK et al. Voluntary wheel running, but not a diet containing (-)-epigallocatechin-3-gallate and $\beta$-alanine, improves learning, memory and hippocampal neurogenesis in aged mice. Behav Brain Res 2014; 272C: 131-140.

49 Acosta S, Jernberg J, Sanberg CD, Sanberg PR, Small BJ, Gemma C et al. NT-020, a natural therapeutic approach to optimize spatial memory performance and increase neural progenitor cell proliferation and decrease inflammation in the aged rat. Rejuvenation Res 2010; 13: 581-588.

50 Pase MP, Scholey AB, Pipingas A, Kras M, Nolidin K, Gibbs A et al. Cocoa polyphenols enhance positive mood states but not cognitive performance: a randomized, placebo-controlled trial. Psychopharmacol 2013; 27: 451-458.

$51 \mathrm{Xu}$ Y, Ku BS, Yao HY, Lin YH, Ma X, Zhang YH et al. The effects of curcumin on depressive-like behaviors in mice. Eur J Pharmacol 2005; 518: 40-46.

52 Richard IH, Schiffer RB, Kurlan R. Anxiety and Parkinson's disease. I Neuropsychiatry Clin Neurosci 1996; 8: 383-392.

53 Sasaki K, El Omri A, Kondo S, Han J, Isoda H. Rosmarinus officinalis polyphenols produce anti-depressant like effect through monoaminergic and cholinergic functions modulation. Behav Brain Res 2013; 238: 86-94.
54 Anandhan A, Tamilselvam K, Radhiga T, Rao S, Essa MM, Manivasagam T. Theaflavin, a black tea polyphenol, protects nigral dopaminergic neurons against chronic MPTP/probenecid induced Parkinson's disease. Brain Res 2012; 1433 104-113.

55 O'Brien EM, Kiely KA, Tipton KF. A discontinuous luminometric assay for monoamine oxidase. Biochem Pharmacol 1993; 46: 1301-1306.

56 Dreiseitel A, Korte G, Schreier P, Oehme A, Locher S, Domani M et al. Berry anthocyanins and their aglycons inhibit monoamine oxidases $A$ and $B$. Pharmacol Res 2009; 59: 306-311.

57 Hou WC, Lin RD, Chen CT, Lee MH. Monoamine oxidase B (MAO-B) inhibition by active principles from Uncaria rhynchophylla. J Ethnopharmacol 2005; 100: 216-220.

58 Lin SM, Wang SW, Ho SC, Tang YL. Protective effect of green tea (-)epigallocatechin-3-gallate against the monoamine oxidase B enzyme activity increase in adult rat brains. Nutrition 2010; 26: 1195-1200.

59 Kang Z, Jiang W, Luan H, Zhao F, Zhang S. Cornin induces angiogenesis through PI3K-Akt-eNOS-VEGF signaling pathway. Food Chem Toxicol 2013; 58: 340-346.

60 Ramirez-Sanchez I, Maya L, Ceballos G, Villarreal F. (-)-epicatechin activation of endothelial cell endothelial nitric oxide synthase, nitric oxide, and related signaling pathways. Hypertension 2010; 55: 1398-1405.

61 Zhang J, Huang XY, Ye ML, Luo CX, Wu HY, Hu Y et al. Neuronal nitric oxide synthase alteration accounts for the role of 5-HT1A-receptor in modulating anxiety-related behaviors. J Neurosci 2010; 30: 2433-2441.

62 Quesseveur G, Gardier AM, Guiard BP. The monoaminergic tripartite synapse: a putative target for currently available antidepressant drugs. Curr Drug Targets 2013; 14: 1277-1294.

63 Martinovich K, Manji H, Lu B. New insights into BDNF function in depression and anxiety. Nat Neurosci 2007; 10: 1089-1093.

64 Gumuslu E, Mutlu O, Sunnetci D, Ulak G, Celikyurt IK, Cine N et al. The antidepressant agomelatine improves memory deterioration and upregulates CREB and BDNF gene expression levels in unpredictable chronic mild stress (UCMS)exposed mice. Drug Target Insights 2014; 8: 11-21.

65 Siuciak JA, Lewis DR, Wiegand SJ, Lindsay RM. Antidepressant-like effect of brainderived neurotrophic factor (BDNF). Pharmacol Biochem Behav 1997; 56: 131-137.

66 Shirayama Y, Chen AC, Nakagawa S, Russell DS, Duman RS. Brain-derived neurotrophic factor produces antidepressant effects in behavioral models of depression. J Neurosci 2002; 22: 3251-3261.

67 Assunção M, Santos-Marques MJ, Carvalho F, Andrade JP. Green tea averts agedependent decline of hippocampal signaling systems related to antioxidant defenses and survival. Free Radic Biol Med 2010; 48: 831-838.

68 Chao MV. Neurotrophins and their receptors: a convergence point for many signaling pathways. Nat Neurosci 2003; 4: 299-309.

69 Segawa M, Morinobu S, Matsumoto T, Fuchikami M, Yamawaki S. Electroconvulsive seizure, but not imipramine, rapidly up-regulates pro-BDNF and t-PA leading to mature BDNF production, in the rat hippocampus. Int I Neuropsychopharmacol 2013; 16: 339-350.

70 Egan MF, Kojima M, Callicott JH, Goldberg TE, Kolachana BS, Bertolino A et al. The BDNF val66met polymorphism affects activity-dependent secretion of BDNF and human memory and hippocampal function. Cell 2003; 112: 257-269.

71 Strauss J, Barr CL, George CJ, Devlin B, Vetro A, Kiss E. Brain-derived neurotrophic factor variants are associated with childhood-onset mood disorder: confirmation in a Hungarian sample. Mol Psychiatry 2005; 10: 861-867.

72 Benjamin S, McQuoid DR, Potter GG, Payne ME, MacFall JR, Steffens DC. The brainderived neurotrophic factor Val66Met polymorphism, hippocampal volume, and cognitive function in geriatric depression. Am J Geriatr Psychiatry 2010; 18: 323-331.

73 Verhagen $M$, van der Meij A, van Deurzen PAM, Janzing JGE, Arias-Vasquez A, Buitelaar JK et al. Meta-analysis of the BDNF Val66Met polymorphism in major depressive disorder: effects of gender and ethnicity. Mol Psychiatry 2010; 15: 260-271.

74 Soliman F, Glatt CE, Bath KG, Levita L, Jones RM, Pattwell SS et al. A genetic variant BDNF polymorphism alters extinction learning in both mouse and human. Science 2010; 327: 863-866.

75 Bath KG, Jing DQ, Dincheva I, Neeb CC, Pattwell SS, Chao MV et al. BDNF Val66Met impairs Fluoextine-induced enhancement of adult hippocampus plasticity. Neuropharmacol 2012; 37: 1297-1304.

76 Ma L, Wang S, Tai F, Yuan G, Wu R, Liu X et al. Effects of bilobalide on anxiety, spatial learning, memory and levels of hippocampal glucocorticoid receptors in male Kunming mice. Phytomedicine 2012; 20: 89-89.

77 Mizuno M, Yamada K, Takei N, Tran MH, He J, Nakajima A et al. Phosphatidylinositol 3-kinase: A molecule mediating bdnf-dependent spatial memory formation. Mol Psychiatry 2003; 8: 217-224.

78 Shi HS, Zhu WL, Liu JF, Luo YX, Si JJ, Wang SJ et al. Pi3k/akt signaling pathway in the basolateral amygdala mediates the rapid antidepressant-like effects of trefoil factor 3. Neuropsychopharmacology 2012; 37: 2671-2683. 
79 Ackermann TF, Kempe DS, Lang F, Lang UE. Hyperactivity and enhanced curiosity of mice expressing PKB/SGK-resistant glycogen synthase kinase-3 (GSK-3). Cell Physiol Biochem 2010; 25: 775-786.

80 Diez H, Garrido JJ, Wandosell F. Specific roles of akt iso forms in apoptosis and axon growth regulation in neurons. PLoS One 2012; 7: e32715.

81 Carter CJ. Multiple genes and factors associated with bipolar disorder converge on growth factor and stress activated kinase pathways controlling translation initiation: Implications for oligodendrocyte viability. Neurochem Int 2003; 50: 461-490.

82 Yang ZZ, Tschopp O, Hemmings-Mieszczak M, Feng J, Brodbeck D, Perentes E et al. Protein kinase $\mathrm{b}$ alpha/akt1 regulates placental development and fetal growth. J Biol Chem 2003; 278: 32124-32131.

83 Tschopp O, Yang ZZ, Brodbeck D, Dummler BA, Hemmings-Mieszczak M, Watanabe $T$ et al. Essential role of protein kinase $b$ gamma (pkb gamma/akt3) in postnatal brain development but not in glucose homeostasis. Development 2005 ; 132: $2943-2954$
84 Leibrock C, Ackermann TF, Hierlmeier M, Lang F, Borgwardt S, Lang UE. Akt2 deficiency is associated with anxiety and depressive behavior in mice. Cell Physiol Biochem. 2013; 32: 766-777.

85 Moreno-Ulloa A, Romero-Perez D, Villarreal F, Ceballos G, Ramirez-Sanchez I. Cell membrane mediated (-)-epicatechin effects on upstream endothelial cell signaling: evidence for a surface receptor. Bioorg Med Chem Lett 2014; 24: 2749-2752.

(c) (1) $\odot$ This work is licensed under a Creative Commons Attributioncc. NonCommercial-NoDerivs 4.0 International License. The images or other third party material in this article are included in the article's Creative Commons license, unless indicated otherwise in the credit line; if the material is not included under the Creative Commons license, users will need to obtain permission from the license holder to reproduce the material. To view a copy of this license, visit http:// creativecommons.org/licenses/by-nc-nd/4.0/ 